\title{
CES
}

COOPERATIVISMO E ECONOMÍA SOCIAL

Núm. 41 (2018-2019), páxs. 227-232

ISSN: $1130-2682$

\section{A VALORACIÓN DA PROBA DE CARGO NOS PROCEDEMENTOS DISCIPLINARIOS DAS COOPERATIVAS (ANOTACIÓN A SENTENZA DA AUDIENCIA PROVINCIAL DE PONTEVEDRA DE 23 DE MAIO DE 2018)}

THE EVALUATION OF THE INCRIMINATING EVIDENCE IN THE DISCIPLINARY COOPERATIVE PROCEEDINGS

(A BRIEF COMMENT ON THE JUDGMENT OF THE COURT OF APPEAL OF PONTEVEDRA, MAY 23 2018)

Julio Costas Comesaña*

Catedrático de Dereito Mercantil, Universidade de Vigo. Dirección de correo electrónico: jcostas@ uvigo.es. 



\section{ANTECEDENTES}

instancia de denuncia presentada por un socio (por entón presidente da
"Cooperativa central de radio taxi" e tamén membro do seu consello rei-
tor), este órgano social acordou o 18.07.2016 a incoación dun expediente disciplinario contra outro socio. De conformidade co art. 25 LCG e baseándose na declaración do denunciante-prexudicado e na localización de ambos os socios no mesmo lugar o día dos feitos denunciados (unha parada de taxis), no acordo de incoación do expediente disciplinario do consello reitor imputa ao socio denunciado un comportamento de "manifesta desconsideración, insultos ou calumnias cara aos membros de consello reitor ou empregados do servizo no exercicio as súas función", tipificando esta conduta, en atención ao disposto no art. 12.1.c) dos estatutos da cooperativa, como unha falta grave, propondo impor ao socio unha sanción económica de 96 euros. Nas alegacións presentadas ao acordo de incoación, o socio denunciado nega os feitos imputados, solicita que se acredite a presenza do socio denunciante no lugar onde supostamente tería lugar os feitos e a presentación dunha proba testifical escrita que corroborase a versión do denunciante. O consello reitor adopta con data 12.08.2016 acordo que pon fin ao procedemento sancionador, no que desestimando as alegacións e considerando acreditados o feitos obxecto da denuncia, resolve que o socio denunciado cometeu unha conduta cualificable como falta grave, e imponlle a sanción disciplinaria de 96 euros.

Seguindo o disposto no art. 25.3.d) LCG, o socio sancionado recorreu o acordo do consello reitor ante o comité de recursos da cooperativa (art. $56 \mathrm{LCG}$ ), que, de oficio, solicitou a un terceiro que informase sobre a presenza dos vehículos dos socios implicados na parada de taxis no día dos feitos. Finalmente, o 11.10.2016 o comité de recursos adoptou o acordo de ratificar o acordo sancionador obxecto do recurso.

Seguindo o disposto nos arts. 25 e 40 LCG, o cooperativista sancionado interpuxo demanda xudicial contra a cooperativa, na que cualifica o acordo sancionador nulo de pleno dereito por vulneración do principio fundamental de presunción de inocencia, como consecuencia de ser imposta a sanción sen unha mínima actividade probatoria. A cooperativa demandada opúxose á demanda, alegando a caducidade do acordo impugnado e a acreditación da falta imputada como consecuencia da proba practicada polos órganos da cooperativa, consistente na declaración do denunciante e na comprobación, a través da actividade dun terceiro, do feito de que os dous taxis dos cooperativistas implicados achábanse na mesma parada no día en que supostamente ocorreron os feitos. Con data 16 de outubro de 2017, o Xulgado do Mercantil núm. 3 de Pontevedra, con sede en Vigo, di- 
tou sentenza desestimatoria, estimando acreditados os feitos imputados coa proba practicada, sen que poidan axuizarse pola xurisdición novamente os feitos que xustificaron a imposición da sanción.

O cooperativista sancionado interpuxo recurso de apelación contra a sentenza de primeira instancia, que considera contraria a dereito. Por sentenza da Sección Primeira da Audiencia Provincial de Pontevedra, de data 23 de maio de 2018 (Roj: SAP PO 666/2018 - ECLI: E:APPO:2018:666), estímase o recurso de apelación, deixando sen efecto a sentenza obxecto do mesmo.

\section{O RÉXIME DE DISCIPLINA SOCIAL NA LEI DE COOPERATIVAS DE GALICIA}

Unha das características que diferencian ao cooperativas respecto das sociedades mercantís, derivada da súa natureza mutualista, radica en que os socios cooperativistas ordinarios asumen unha dobre condición xurídica, como aportante do capital social cooperativo subscrito e como usuario da actividade cooperativizada, a través da cal tratan de alcanzar a vantaxe mutualista que motiva a súa pertenza á cooperativa. Como consecuencia desta natureza — pero tamén debido a outras características da cooperativas, como o seu carácter de sociedade personalista ou de propiedade conxunta-, todas as leis españolas de cooperativas impoñen aos socios cooperativistas un número de obrigas e/ou deberes fronte á cooperativa significativamente maior que o existente nas sociedades mercantís, particularmente, nas sociedades de capital, onde a única obriga legal que asumen os socios pode ser a de realizar a achega ao capital social comprometida.

A Lei de Cooperativas de Galicia (LCG), de aplicación na sentenza anotada, enuncia as "obrigas do socio" no art. 24. No en tanto, non se trata dunha enumeración pechada de obrigas e deberes sociais do cooperativista, senón dun numerus apertus que, nin sequera, contén as obrigas mínimas ou básicas do socio; obrigas e deberes do socio fronte á cooperativa que atopamos noutros preceptos da LCG e que teremos que buscar nos estatutos, pero tamén no regulamento de réxime interno ou nos acordos adoptados pola asemblea xeral da cooperativa (para unha clasi-

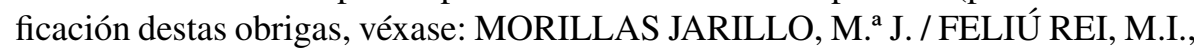
Curso de cooperativas, Ed. Tecnos, Madrid, Tomo I, $3^{\mathrm{a}}$ ed., 2018, pp. 248-255). Este é o caso de autos, pois de acordo co texto da sentenza anotada, os estatutos da cooperativa demandada tipificarían como falta grave o trato desconsiderado ou vexatorio cara a outro socio, sancionable con multa.

Entre as obrigas legais do socio, o propio art. 24, letra b) LCG sinala a de "Cumpri-os deberes legais e estatutarios, así como vos acordos validamente adoptados polos órganos sociais da cooperativa". Esta obriga de cumprir as normas de organización social complétase coa obriga legal da cooperativa de regular nos estatutos as normas de disciplina social, que no exercicio da súa autonomía da 
vontade terá de respectar as regras imperativas que ao efecto dispón o art. 25 LCG. En consecuencia, os estatutos ou, no seu caso, o regulamento de réxime interno ou por acordo da asemblea xeral deben tipificar que condutas do socio constitúen falta (clasificándoas en leves, graves ou moi graves), as sancións que pola súa comisión pódense impor (que poden ser: económicas, de suspensión de dereitos sociais e de expulsión da cooperativa), o procedemento sancionador que ha de seguir o órgano social que teña atribuída tal potestade sancionadora (o órgano de administración, sendo indelegable esta competencia: art. 25.3.a LCG) e os recursos que poida interpor o socio sancionado; normas de disciplina social que doutrina e xurisprudencia destacan han de ser redactadas con claridade e precisión, co obxecto de preservar a seguridade xurídica, evitar un exercicio arbitrario da potestade disciplinaria e diminuír a litigiosidad en beneficio de socio e a boa marcha da cooperativa como organización social e empresarial.

En beneficio da seguridade xurídica e en prexuízo da ampla capacidade de autorregulación das cooperativas, ente outras cuestións, o art. 25, no seu apartado 2, regula o sistema de prescrición das faltas (non se regula, pola contra, a prescrición das sancións impostas), en tanto que o apartado 3 establece o sistema de recursos que proceden fronte á resolución do órgano social sancionador; en particular, dispón que o acordo sancionador ou, no seu caso, o acordo de ratificación (do comité de recursos ou da asemblea xeral) é susceptible de ser recorrido ante a xurisdición ordinaria (Xulgado do Mercantil competente por razón do domicilio social da cooperativa: art. 86 ter.2.a) da Lei Orgánica do Poder Xudicial) pola canle procesual que regula o art. 40 LCG para a impugnación dos acordos adoptados pola asemblea xeral da cooperativa.

\section{A DOUTRINA DA SENTENZA}

Non é obxecto de discusión a natureza sancionadora do procedemento privado de disciplina social que regula a LCG e, por tanto, sobre a aplicabilidade ao mesmo -entre outros- dos principios de legalidade e tipicidade propios dos procedementos sancionadores públicos. Principios que se poden observar no art. 25.1 LCG, cando dispón que os socios só poden ser sancionados por condutas previamente tipificadas como faltas (as moi graves e graves, nos estatutos; as leves poden estalo no regulamento de réxime interno ou por acordo da asemblea xeral), a través do procedemento establecido nos estatutos, con audiencia do interesado, sen que se lle poida impor ao socio unha sanción que non estea expresamente prevista nos estatutos. Con todo, chama a atención, desde a perspectiva da aplicabilidade a estes procedementos disciplinarios dos principios do dereito sancionador público, que a LCG, e ningunha das restantes leis de cooperativas de España, esixan a separación formal entre as fases de instrución e resolución do expediente disciplinario (esixido polo art. 63.1 da Lei 39/2015, de 1 de outubro, do Procedemento Administrativo Común das Administracións Públicas). Entendemos que, 
para maior garantía de independencia na tramitación do procedemento, os estatutos deberían dispor que, radicando como dispón a LCG a potestade disciplinaria no órgano de administración da cooperativa, o instrutor do expediente non debe participar na resolución do mesmo. De igual modo, debería garantirse que unha composición do comité de recursos imparcial e independente a través dunha regulación expresa das situación de potenciais conflitos de interese entre as partes e da recusación do instrutor e dos membros do órgano sancionador.

A diferenza entre as partes obxecto da sentenza anotada radica na suficiencia ou insuficiencia da proba de cargo incorporada ao expediente disciplinario e, por tanto, no respecto ou non polo órgano sancionador dos principios acusatorio e de presunción de inocencia. A xuízo do Xuíz do Mercantil, a declaración do socio prexudicado (ofendido) e a proba de oficio realizada polo órgano sancionador dirixida a verificar a presenza de ambos os socios no lugar dos feitos no día que tiveron lugar, é suficiente para desvirtuar a presunción de inocencia do socio. Pola contra, a sentenza de apelación considera que esa proba practicada non é suficiente proba de cargo para anular a presunción de inocencia de que goza o acusado, razón pola que anula o acordo sancionador e a sentenza de primeira instancia. En concreto, a Audiencia Provincial afirma que "No expediente sancionador non atopamos proba algunha de cargo que permita obter a convicción sobre a participación nos feitos do recorrente, pois aquela limitouse a dotar de credibilidade á denuncia, sen unha mínima comprobación. Foi só posteriormente, unha vez que o recorrente formulou a súa queixa contra o acordo [...] no que se lle impuña a sanción, cando o comité de recursos practicou de oficio unha proba supostamente de cargo consistente en pedir a un terceiro, (ao que se identifica, sen maior detalle, como "Demesix") un documento que supostamente acreditaría a presenza simultánea dos dous vehículos en [...] lugar onde supostamente producíronse os feitos imputados. Sucede que esta dilixencia, -extemporáneamente practicada, pois a sanción xa fora imposta-, non enche as esixencias da proba indiciaria, pois non entendemos razoable a inferencia de que os feitos sucederon tal como relatounos o denunciante polo só dato da presenza dos dous vehículos no mesmo lugar".

En definitiva, neste caso, existe entre a AP de Pontevedra e o Xuíz do Mercantil unha distinta valoración da proba incorporada ao expediente disciplinario, e debemos considerar acertada a posición da Audiencia Provincial, por canto as normas de disciplina social cooperativa, en tanto que normas sancionadoras e limitativas de dereitos, deben ser obxecto de interpretación restritiva (neste sentido: STS de 28 de decembro de 2000. Roj: STS 9714/2000 - ECLI: E:TS:2000:9714), e, por iso, cando existen dúbidas razoables sobre a existencia ou relevancia xurídica dos feitos imputados ou respecto da autoría dos mesmos, tal dúbida hase de resolver a favor do socio imputado (indubio pro reo), considerando non acreditados os feitos imputados ou a autoría dos mesmos. 